\title{
Effect of Dexamethasone as an Adjuvant To 0.5\% Bupivacaine in Supraclavicular Brachial Plexus Block- A Randomized Study.
}

\author{
Padmaja J', Jaganath $\mathrm{A}^{2}$, Srinivasan K V. \\ ${ }^{1}$ Assistant Professor, Department of Anaesthesiology, Viswavabahrati Medical College, Penchikalapadu, Kurnool, Andhra Pradesh, ${ }^{2}$ Assistant Professor \\ Department of Anaeshesiology, PESIMSR, Kuppam, Andhra Pradesh, ${ }^{3}$ Professor, PESIMSR, Kuppam, Chittoor District, Andhra Pradesh.
}

\section{Abstract}

Background: Aims and Objectives: To study the effects of addition of Dexamethasone to Bupivacaine with respect to onset, duration of sensory and motor blockade, haemodynamic variables and rescue analgesics used in first 24 hours. Subjects and Methods: A prospective, randomized, study of 100 patients of ASA I \&II, aged between 20-60years were included. Patients were randomized to two groups, 50 of bupivacaine group (B) and 50 of bupivacine and dexamethasone (BD). Brachial plexus block was performed via supracalvicular route using ultrasound machine. The onset of anesthesia, loss of sensory perception and temperature was recorded. The patients were also monitored for any side effects or complications. The data obtained was analyzed using (SPSS vs 18). Quantitative data were analyzed by using student ' $t$ ' test, Qualitative by using Chi - Square test. p value of less than 0.05 was considered as statistically significant. Results: Demographics were comparable between the groups. The mean onset of sensory block [10.3 Vs 16.7] and motor block [5.6 \pm 0.7 Vs8.6 \pm 1.2$]$ was earlier in BD group. Similarly the mean duration of sensory block in hours [5.9 \pm 0.67 Vs $4 \pm 6.3$ ] and motor block was [4.3 \pm 0.9 Vs1.9 \pm 0.5$]$. The group BD received less rescue analgesics. There was a significant fluctuation in systolic blood pressure in group B. Conclusion: Use of dexamethasone as an adjuvant to bupivacaine in supraclavicular brachial plexus block results in faster onset of action of sensory and motor blockade. It also results statistically significant longer duration of sensory and motor blockade.

Keywords: Dexamethasone, Bupivacaine, Supraclavicular Brachial Plexus Block.

Corresponding Author: Dr Jaganath A, Assistant Professor Department of Anaeshesiology, PESIMSR, Kuppam, Andhra Pradesh.

Received: August 2019

Accepted: August 2019

\section{Introduction}

Anesthetizing patients using supraclavicular brachial plexus block for upper limb surgeries is a popular technique and it is a good and effective alternative option to general anaesthesia. ${ }^{[1]}$ It is safe and cost-effective, produces muscle relaxation facilitating surgery, it avoids upper airway instrumentation resulting in stable intraoperative hemodynamics, and has better analgesic profile in postoperative period. ${ }^{[1,2]}$

Bupivacaine is a long acting local anesthetic agent. Many adjuvants e.g- Fentanyl, Neostigmine, Midazolam, Clonidine, Dexmedetomidine etc have been used to enhance the quality and duration of postoperative pain. ${ }^{[3]}$ Corticosteroids have been used as adjuvants in supraclavicular brachial plexus and have been shown to result in better postoperative analgesic profile than local anesthetic agents alone. ${ }^{[1]}$ Dexamethasone is a corticosteroid having potency of 40 times to that of Hydrocortisone. Studies have been conducted and proven dexamethasone as an effective adjuvant in supraclavicular brachial plexus block. ${ }^{[11-14,18]}$

\section{Aims and Objectives:}

To study the effects of Inj.dexamethasone $8 \mathrm{mg}$ as an adjuvant to $0.5 \%$ Inj.bupivacaine in supraclavicular brachial plexus block with respect to onset and duration of sensory and motor blockade, and rescue analgesics used in first 24 hours.

\section{Subjects and Methods}

This is a prospective, randomized, single blinded study, conducted after obtaining approval from Institutional Ethics committee conducted in a 750 bedded tertiary care hospital. Hundred patients scheduled to undergo upper limb surgery were included. After obtaining written and informed consent, patients were sequentially, randomized by envelope method into two equal groups. Patients in Group-I (B) received $20 \mathrm{ml}$ of $0.5 \%$ Inj.bupivacaine whereas those in Group-II (BD) received $18 \mathrm{ml}$ of $0.5 \%$ Inj.bupivacaine with $8 \mathrm{mg}$ of Inj.dexamethasone added. Supraclavicular plexus block was performed using 6-13Mhz linear ultrasound probe.

The inclusion criteria were ASA-I, II patients aged between 20 to 60 years scheduled for upper limb surgeries. Exclusion criteria were ASA-III and above, bleeding diathesis, abnormal coagulation profile, puncture site infection, difficult airway, severe anemia, hypovolemia, shock, hypersensitivity to local anesthetic agents or dexamethasone. Preanesthetic evaluation was performed in all patients and 


\section{0}

necessary blood investigations, electrocardiogram and other tests were asked as needed. Intraoperative monitors included electrocardiogram (ECG), non-invasive blood pressure (NIBP) and plethysmography (SpO2).

The motor block was assessed using Bromage three point score $[0=$ normal motor function with full flexion and extension of elbow, wrist and fingers, $1=$ decreased motor strength with ability to move fingers and/or wrist only, $2=$ complete motor blockade with inability to move fingers]. The time of motor blockade was noted. The time of onset of sensory block was defined as the time elapsed between the injection of drug and complete loss of cold perception of the hand, while onset of the motor blockade was defined as the time elapsed from injection of drug to complete the motor block. Duration of sensory block which is the time elapsed between the injection of drug and appearance of pain requiring analgesia and duration of motor block was also recorded.

The patients were also monitored for any adverse effects of study medications or complications associated with the supraclavicular block.

Diclofenac sodium intra-muscular injection was used as rescue analgesic whenever patients complained of pain. The numbers of rescue analgesics in 24 hours of post-operative period were also recorded.

The data thus obtained was analyzed using Statistical Package for Social services. (SPSS vs 18). Quantitative data was analyzed by using student ' $t$ ' test. Qualitative data was analyzed using Chi-Square test. $\mathrm{P}$ value of less than 0.05 was considered as statistically significant.

\section{Results}

About 100 patients of ASA I and II posted for upper limb surgeries were enrolled in this study as study subjects.

\section{Table 1: Demographics}

\begin{tabular}{|l|l|l|l|}
\hline \multirow{2}{*}{ Age group } & \multicolumn{4}{|l|}{ Treatment group } \\
\cline { 2 - 4 } & $\begin{array}{l}\text { Bupivacain } \\
\text { e Group n } \\
(\boldsymbol{\%})\end{array}$ & $\begin{array}{l}\text { Bupivacaine } \\
\text { Dexamethason } \\
\text { e group n }(\boldsymbol{\%})\end{array}$ & Total n (\%) \\
\hline Less than 30 years & $12(26.7)$ & $12(23.3)$ & $24(25.0)$ \\
\hline $31-40$ years & $23(43.3)$ & $34(70.0)$ & $57(56.7)$ \\
\hline $41-50$ years & $11(23.3)$ & 0 & $13(11.7)$ \\
\hline 51 years and above & $4(6.7)$ & $4(6.7)$ & $8(6.7)$ \\
\hline Total & $50(100)$ & $50(100)$ & $100(100)$ \\
\hline Mean \pm SD & $36.9 \pm 10.4$ & $34.7 \pm 7.1$ & $35.8 \pm 8.9$ \\
\hline
\end{tabular}

$t^{*}$ value $=0.986$ and $p$ value $-0.328 \mathrm{NS}$

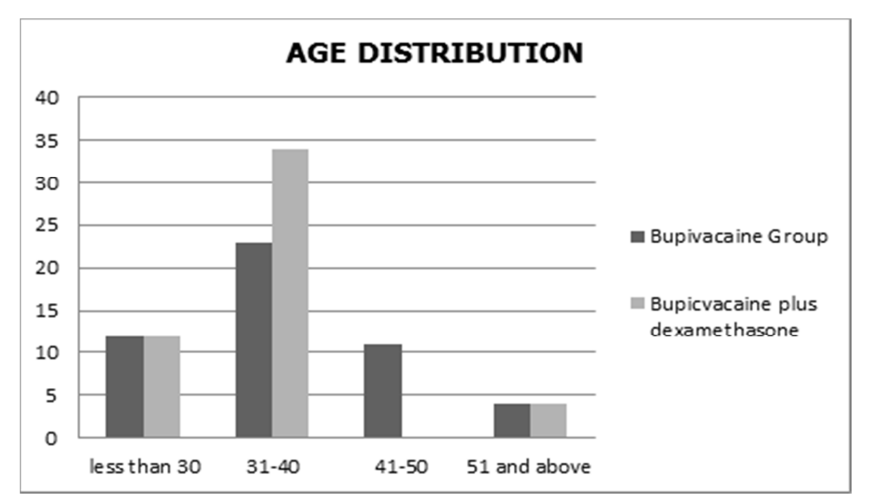

Figure 1: Demographics
The mean age of patients who received Bupivacaine was 36.9 years and those who received Bupivacaine plus Dexamethasone was 34.7 years. There was no statistically significant difference between the mean ages of two groups. About $43.3 \%$ of the patients in group 1 and $70.0 \%$ of the patients in group 2 belonged to $31-40$ years age group. Since the age groups were similar the groups were comparable by age.

\begin{tabular}{|l|l|l|l|l|}
\hline Table 2: Onset of sensory block between the study groups \\
\hline Groups & Bupivacaine & $\begin{array}{l}\text { Bupivacaine } \\
\text { And } \\
\text { Dexamethasone }\end{array}$ & $\begin{array}{l}\text { T } \\
\text { Value }\end{array}$ & P Value \\
\hline $\begin{array}{l}\text { Onset of } \\
\text { sensory } \\
\text { block } \\
\text { (Min) } \\
\text { Mean } \pm \text { SD }\end{array}$ & $16.7 \pm 2.1$ & $10.3 \pm 1.4$ & 13.921 & $<0.001$ \\
& & & & Significant \\
\hline
\end{tabular}

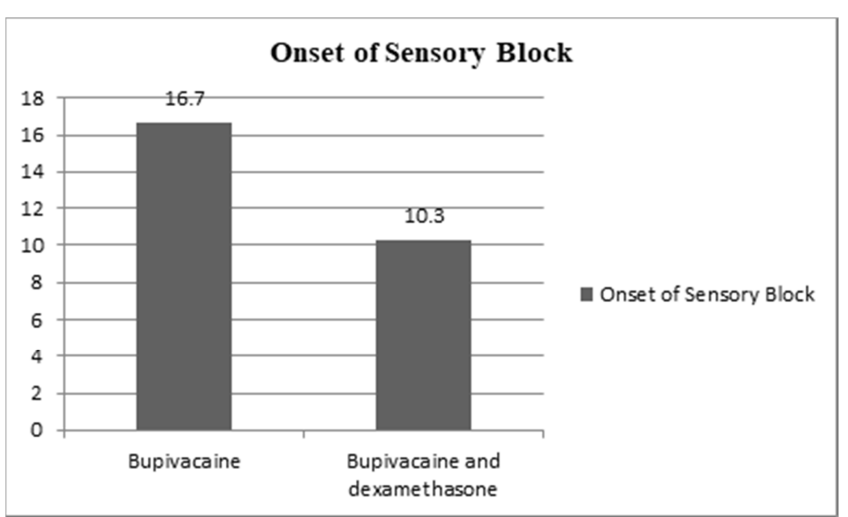

\section{Figure 2: Onset of sensory Block between study groups}

The mean time of onset of sensory block in Bupivacaine group was 16.7 minutes and 10.3 minutes in Bupivacaine plus Dexamethasone group. This difference in onset of sensory block was statistically significant between the two groups.

\begin{tabular}{|c|c|c|c|c|}
\hline Groups & Bupivacaine & $\begin{array}{l}\text { Bupivacaine } \\
\text { and } \\
\text { Dexamethasone }\end{array}$ & t Value & p value \\
\hline 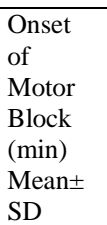 & $8.6 \pm 1.2$ & $5.6 \pm 0.7$ & 11.997 & $\begin{array}{l}<0.001 \\
\text { Significant }\end{array}$ \\
\hline
\end{tabular}

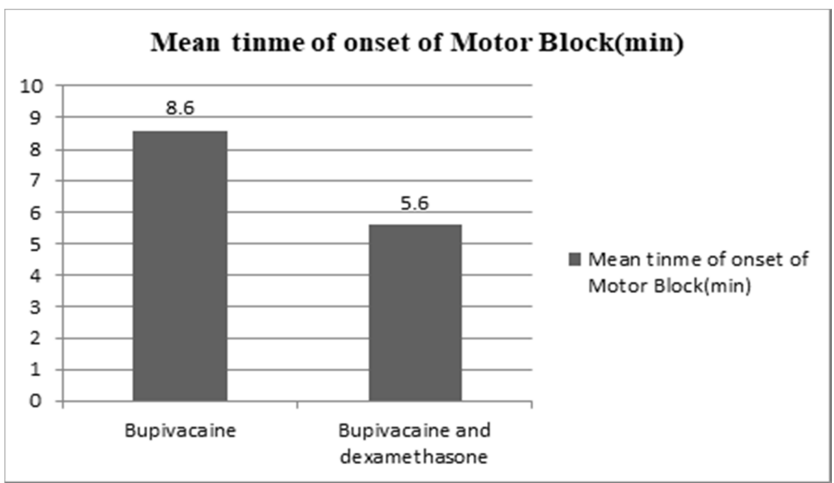

Figure 3: Mean time of onset of Motor Block in treatment groups 
0

The mean time of onset of motor block in this study in Bupivacaine group was $8.6( \pm 1.2)$ minutes and the mean onset of motor block in Bupivacaine plus Dexamethasone group was $5.6( \pm 0.7)$ minutes. There is significant difference between the onset of motor block in minutes in Bupivacaine and Bupivaciane plus Dexamethasone groups.

\begin{tabular}{|c|c|c|c|c|}
\hline Groups & Bupivacaine & $\begin{array}{l}\text { Bupivacane } \\
\text { and } \\
\text { Dexamethasone }\end{array}$ & $\begin{array}{l}\mathrm{t} \\
\text { value }\end{array}$ & p value \\
\hline $\begin{array}{l}\text { Duration of } \\
\text { Sensory } \\
\text { Block(HRS) } \\
\text { Mean } \pm \text { SD }\end{array}$ & $4.0 \pm 6.3$ & $5.9 \pm 07$ & -1.7 & $\begin{array}{l}<0.005 \\
\text { Significant }\end{array}$ \\
\hline
\end{tabular}

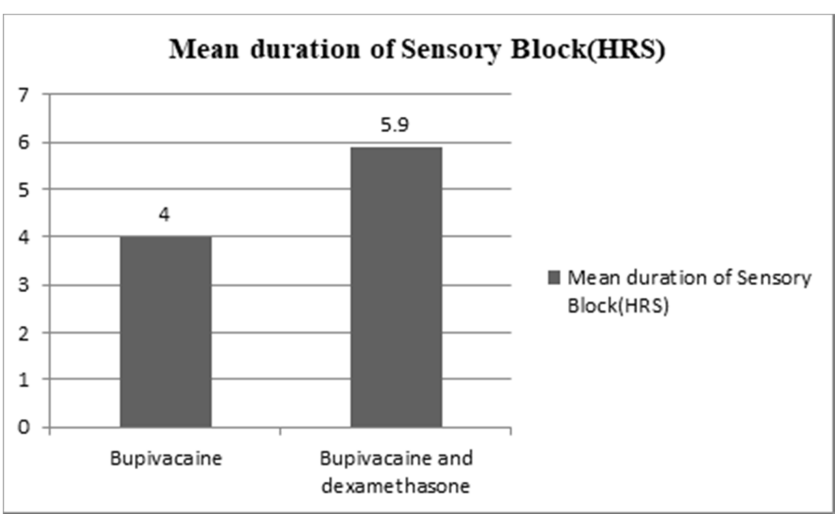

Figure 4: Mean duration of Sensory block in treatment group

The mean duration of sensory block in Bupivacaine group was $4( \pm 6.3)$ hours and in Bupivacine plus Dexamethasone group was $5.9( \pm 0.7)$ hours. This difference was not statistically significant between the Bupivacaine and Bupivacaine plus Dexamethasone groups.

Table 5: Duration of Motor Block between study group

\begin{tabular}{|l|l|l|l|l|}
\hline Groups & Bupivacaine & $\begin{array}{l}\text { Bupivacaine } \\
\text { and } \\
\text { Dexamethasone }\end{array}$ & $\begin{array}{l}\text { t } \\
\text { value }\end{array}$ & p value \\
\hline $\begin{array}{l}\text { Duration of } \\
\text { Motor } \\
\begin{array}{l}\text { Block(HRS) } \\
\text { Mean } \pm \text { SD }\end{array}\end{array}$ & $1.9 \pm 0.5$ & $4.3 \pm 0.9$ & 14.868 & $<0.001$ \\
Significant
\end{tabular}

\section{Mean duration of Motor Block(HRS)}

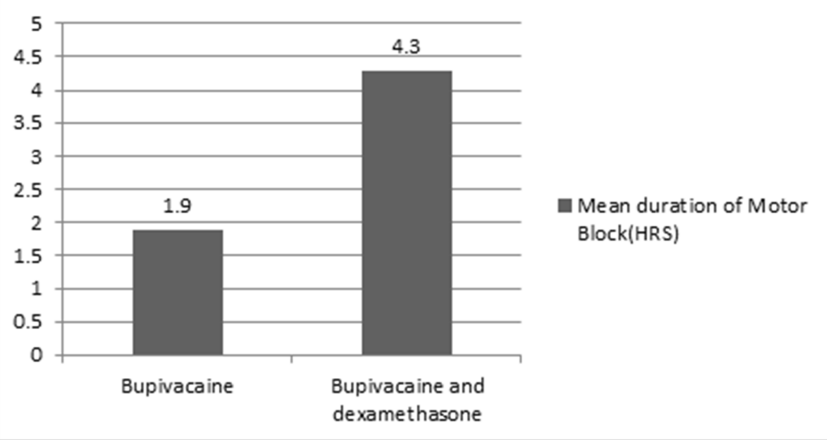

Figure 5: Mean duration of Motor Block in study group

The mean duration of sensory block in Bupivacaine group was $4 \pm 6.3$ hours and in Bupivacine plus Dexamethasone group was $5.9 \pm 0.7$ hours. This difference was not statistically significant between the Bupivacaine and Bupivacaine plus Dexamethasone groups.

Table 6: Number of Rescue Analgesics (RA) in 24 Hrs between the study group

\begin{tabular}{|l|l|l|l|l|}
\hline Groups & Bupivacaine & $\begin{array}{l}\text { Bupivacaine } \\
\text { and } \\
\text { Dexamethasone }\end{array}$ & $\begin{array}{l}\mathbf{t} \\
\text { value }\end{array}$ & p value \\
\hline $\begin{array}{l}\text { No. of RA } \\
\text { in 24Hrs } \\
\text { Mean } \pm \text { SD }\end{array}$ & $2.5 \pm 0.5$ & $1.3 \pm 0.4$ & 9.693 & $\begin{array}{l}<0.001 \\
\text { Significant }\end{array}$ \\
\hline
\end{tabular}

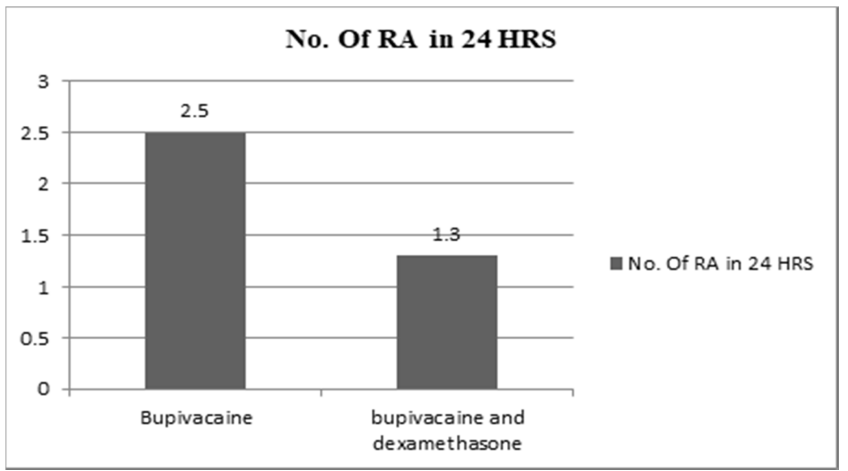

Figure 6: No. Of Resuce Analgesics In 24 Hrs

Table 7: Pulse rate at different time intervals between the study group

\begin{tabular}{l} 
Table 7: Pulse rate at different time intervals between the study group \\
\cline { 2 - 6 }
\end{tabular}

[Table and Figure 6] show the distribution of the study groups about the number of rescue analgesic doses in 24 hours. The patients of Bupivaciane group had received 2.5 ( \pm $0.5)$ doses and the patients of Bupivacaine plus
Dexamethasone group received 1.3 mean doses of rescue analgesic. The difference in receiving the mean doses of rescue analgesic was statistically significant between the Bupivacaine and Bupivacaine plus Dexamethasone groups 


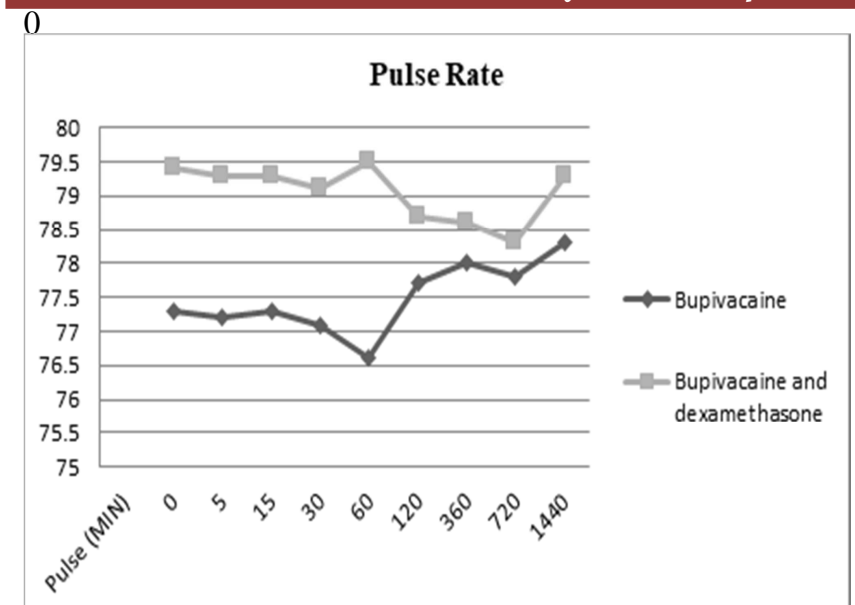

Figure 7: Pulse rate at different time intervals between the study group

The mean heart rate in Bupivacaine group was around 76 to 78 beats per minute. The mean heart rate in Bupivacaine plus Dexamethasone group was around 78 to 79 beats per minute. There was no statistically significant difference between Bupivacaine and Bupivacaine plus Dexamethasone groups in Heart rate at different time intervals.

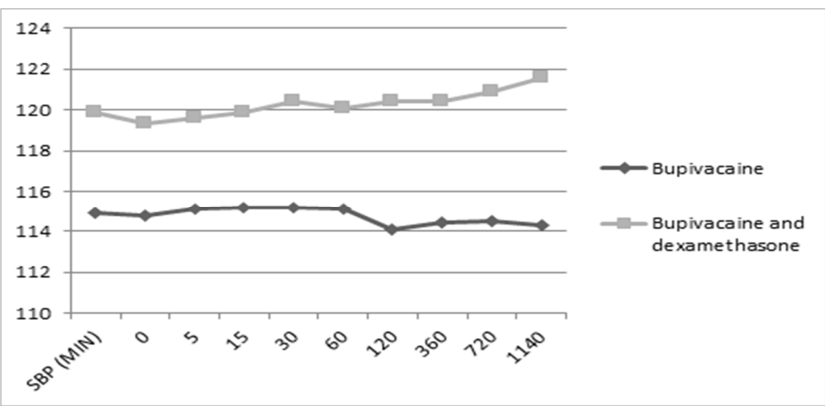

Figure 8: Mean systolic blood pressure at different intervals of time after anaesthesia

The mean systolic blood pressure in Bupivacaine group ranged from $114.1 \pm 8.8 \mathrm{~mm}$ of $\mathrm{Hg}$ to $115.2 \pm 9.4 \mathrm{~mm}$ of $\mathrm{Hg}$. The mean systolic blood pressure in Bupivacaine plus Dexamethasone group was ranging from $119.3 \pm 12.8 \mathrm{~mm}$ of $\mathrm{Hg}$ to $120.9 \pm 13.1 \mathrm{~mm}$ of $\mathrm{Hg}$ at different time intervals. The difference in systolic blood pressures at different time intervals between Bupivacaine and Bupivaciane plus Dexamethasone groups were not statistically significant in the initial time but there was a significant difference between the two groups in systolic blood pressures after 2 hours till 24 hours.

\section{Table 8: Systolic blood pressure at different time intervals between the treatment}

Table 8: Systolic blood pressure at different time intervals between the treatment
\begin{tabular}{|l|l|l|l|l|l|}
\hline \multirow{2}{*}{ SBP } & \multicolumn{2}{|c|}{ Mean \pm SD } & t value & p value & \multirow{2}{*}{ Significance } \\
\cline { 2 - 6 } & Bupivacaine & Bupivacaine and Dexamethasone & & & \\
\hline 0 Min & $114.9 \pm 9.3$ & $119.9 \pm 12.8$ & -1.71 & 0.093 & NS \\
\hline 5 Min & $114.8 \pm 8.7$ & $119.3 \pm 12.7$ & -1.615 & 0.112 & NS \\
\hline 15 Min & $115.1 \pm 9.0$ & $119.6 \pm 12.8$ & -1.586 & 0.118 & NS \\
\hline 30 Min & $115.2 \pm 9.4$ & $119.9 \pm 12.9$ & -1.601 & 0.115 & NS \\
\hline 60 Min & $115.1 \pm 8.0$ & $120.4 \pm 12.7$ & -1.949 & 0.056 & NS \\
\hline 120 Min & $114.1 \pm 8.8$ & $120.1 \pm 12.5$ & -2.151 & 0.036 & SIG \\
\hline 360 Min & $114.4 \pm 8.8$ & $120.4 \pm 13.2$ & -2.069 & 0.043 & SIG \\
\hline 720 Min & $114.5 \pm 8.9$ & $120.9 \pm 13.1$ & -2.165 & 0.035 & SIG \\
\hline 1140 Min & $114.3 \pm 9.1$ & $121.6 \pm 13.0$ & -2.527 & 0.014 & SIG \\
\hline
\end{tabular}

NS- Not Significant; SIG- significant

Table 9: Diastolic blood pressure at different time intervals between the treatment groups

\begin{tabular}{|c|c|c|c|c|c|}
\hline \multirow[t]{2}{*}{ DBP } & \multicolumn{2}{|c|}{ Mean \pm SD } & \multirow[t]{2}{*}{ t value } & \multirow[t]{2}{*}{ p value } & \multirow[t]{2}{*}{ Significance } \\
\hline & Bupivacaine & Bupivacaine and Dexamethasone & & & \\
\hline $0(\mathrm{~min})$ & $76.3 \pm 7.4$ & $77.7 \pm 7.3$ & -0.735 & 0.465 & NS \\
\hline $5(\min )$ & $76.1 \pm 6.8$ & $78.0 \pm 7.1$ & -1.041 & 0.302 & NS \\
\hline $15(\min )$ & $75.7 \pm 6.4$ & $78.4 \pm 7.0$ & -1.581 & 0.119 & NS \\
\hline $30(\min )$ & $76.9 \pm 6.5$ & $78.7 \pm 7.4$ & -0.961 & 0.34 & NS \\
\hline $60(\min )$ & $75.8 \pm 6.3$ & $78.3 \pm 7.5$ & -1.377 & 0.174 & NS \\
\hline $120(\mathrm{~min})$ & $76.7 \pm 6.0$ & $77.9 \pm 7.9$ & -0.622 & 0.536 & NS \\
\hline 360 (min) & $76.5 \pm 6.7$ & $77.6 \pm 7.9$ & -0.567 & 0.573 & NS \\
\hline $720(\mathrm{~min})$ & $75.5 \pm 5.9$ & $77.5 \pm 7.2$ & -1.135 & 0.261 & NS \\
\hline $1140(\min )$ & $75.9 \pm 6.1$ & $77.5 \pm 6.9$ & -0.914 & 0.365 & NS \\
\hline
\end{tabular}

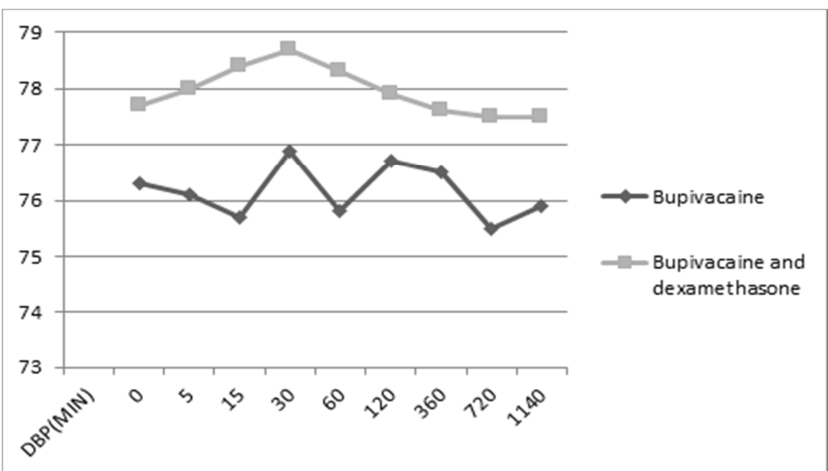

Figure 9: Diastolic blood pressure at different time intervals between the treatment groups

\section{Discussion}

Supraclavicular brachial plexus block is one of the safe and cost-effective methods of anaesthetizing patients for upper limb surgeries. This technique defers the necessity of manipulation of upper airway and has the advantage of good postoperative analgesic profile. ${ }^{[2,3]}$

Bupivacaine, is a long acting local anaesthetics used in supraclavicular brachial plexus block. Patchy, incomplete analgesia and delayed action are the drawbacks of use of bupivacaine and hence many adjuvant medications have been used for nerve plexus block. ${ }^{[4]}$

Dexamethasone is a glucocorticoid and has been used as an adjuvant to bupivacaine for its added analgesic effect. ${ }^{[4,5,11,12]}$ 
0

However very few studies have been conducted to assess the effects of dexamethasone as an adjuvant to bupivacaine and hence we undertook this research work.

The mean ages of the patients were 36.9 years in Bupivacaine group and 34.7 in Bupivacaine-Dexamethasone group and were statistically insignificant and were comparable with other studies. ${ }^{[5,12]}$

The mean time of onset of sensory blockade was statistically significant ( $\mathrm{p}$ value) between Group-B (16.7 minutes) and Group-BD (10.3 minutes) and the mean time of onset of motor blockade in Group-B $8.6 \pm 1.2$ minutes when compared to Group-BD $5.6 \pm 0.7$ minutes and it was statistically significant ( $\mathrm{p}$ value). Addition of dexamethasone to bupivacaine resulted in statistically significant faster onset of action of sensory and motor blockade comparable with other studies. ${ }^{[3,12]}$

The mean duration of sensory blockade in Group-B was 4.6 \pm 0.3 hours and $5.9 \pm 0.7$ hours in Group-BD ( $p$ value) whereas the mean duration of motor block in Group-B was $1.9 \pm 0.5$ hours and $4.3 \pm 0.9$ hours in Group-BD and the difference was statistically significant ( $p$ value). Results of our study were comparable with other studies conducted by other authors. ${ }^{[5,11,12]}$ The findings of our study along with the studies of other authors suggests that dexamethasone as an adjuvant to bupivacaine results in faster onset of action and prolongs the duration of sensory and motor blockade. This might be due anti-inflammatory effect of Dexamethasone. Mean consumption of rescue analgesics were lesser in Group-BD than in Group-B and were comparable with other study. ${ }^{[3]}$

Addition of $8 \mathrm{mg}$ of dexamethasone to bupivacaine is safe and effective in achieving faster onset of sensory and motor blockade and also in resultant longer duration of sensory blockade. We did not notice complications in either group with respect to supraclavicular brachial plexus block, bupivacaine or with the use of dexamethasone as an adjuvant.

It is a single blind study and hence bias cannot be ruled out. Further research using bigger sample sizes are needed to study the beneficial or adverse effects of dexamethasone as an adjuvant to bupivacaine in supraclavicular brachial plexus block.

\section{Conclusion}

Use of dexamethasone as an adjuvant to bupivacaine in supraclavicular brachial plexus block results in faster onset of action of sensory and motor blockade. It also results statistically significant longer duration of sensory and motor blockade.

\section{References}

1. Bazin JE, Massoni C, Bruelle P, Fenies V, Groslier D, Schoeffler P. The addition of local anesthetics in brachial plexus block: The comparative effects of morphine, buprenorphine and sufentanil. Anaesthesia 1997;52:858-62.

2. Singam A, Buprenorphine as an adjuvant in supraclavicular brachial plexus block, IJBAR, 2012:03:07: $571-5$.

3. Yadav RK, Sah BP, Kumar P, Singh SN, et al., Effectiveness of addition of neostigmine or dexamethasone to local anesthetic in providing perioperative analgesia for brachial plexus block: A prospective, randomized, double blinded, controlled study. Kathmandu University Medical Journal 2008;6(1):302-309.

4. Estebe JP,Le Corre P, Clément R, Du Plessis L, Chevanne F, Le Verge $\mathrm{R}$, Ecoffey C. Effect of dexamethasone on motor brachial plexus block with bupivacaine and with bupivacaine-loaded microspheres in a sheep model. European Journal of Anaesthesiology 2003:305-310.

5. Honorio T. Benzon, Epidural Steroids. In P. Prithvi Raj. Pain medicine, a comprehensive review. Mosby publications 1999.p.259- 263.

6. Shrestha BR, Maharjan SK, Tabedar S et al., Supraclavicular brachial plexus block with and without dexamethasone - a comparative study. Kathmandu Univ Med J (KUMJ). 2003 Jul-Sep;1(3):158-60.

7. Shrestha BR, Mahajan SK, Shrestha G, Goutham B, et al., Comparative study between tramadol and dexamethasone as an admixture to bupivacaine in supraclavicular brachial plexus block. J Nepal Med Assoc 2007;46(168):158-64.

8. Islam SM, Hossain MHMD, Maruf AA,et al., Effect of addition of Dexamethasone to local anesthetics in supraclavicular brachial plexus block. JAFMC Bangladesh 2011;7(1):11-14.

9. Chattopadhyay S, Mitra LG, Tramadol as an adjuvant for Brachial plexus block, J Anaeth Clin Pharmacol, 2007;23(2):187-9.

10. Pham - Dang C, Gunst J, Gouin J, Gouin F, Poirier P, Touchais S, et al, A novel Supraclavicular Approach to Brachial Plexus Block, Anesth Analg 1997;85:111-16

11. Dalens B, Vanneuville G, Tanguy A, A new parascalene approach to the brachial plexus in Children: Comparison with the supraclavicular approach, Anesth Analg 1987;66:1264-71.

12. Curley J, Castillo J, Hotz J, Uezono M, Hernandez S, Lim J, et al. Prolonged regional nerve blockade: Injectable biodegradable bupivacaine/polyester microspheres. Anesthesiology. 1996;84:1401-10.

13. Castillo J, Curley J, Hotz J, Uezono M, Tigner J, Chasin M, et al. Glucocorticoids prolong rat sciatic nerve blockade in vivo from Bupivacaine microspheres. Anesthesiology. 1996;85:1157-66.

14. Kopacz DJ, Lacouture PG, Wu D, Nandy P, Swanton R, Landau C. The dose response and effects of Dexamethasone on Bupivacaine microcapsules for intercostal blockade (T9 to T11) in healthy volunteers. Anesth Analg. 2003;96:576-82.

Copyright: (C) the author(s), publisher. Academia Anesthesiologica International is an Official Publication of "Society for Health Care \& Research Development". It is an open-access article distributed under the terms of the Creative Commons Attribution Non-Commercial License, which permits unrestricted non-commercial use, distribution, and reproduction in any medium, provided the original work is properly cited.

How to cite this article: Padmaja J, Jaganath A, Srinivasan KV. Effect of Dexamethasone as an Adjuvant To 0.5\% Bupivacaine in Supraclavicular Brachial Plexus Block- A Randomized Study.. Acad. Anesthesiol. Int. 2019;4(2):113-117.

DOI: dx.doi.org/10.21276/aan.2019.4.2.27

Source of Support: Nil, Conflict of Interest: None declared. 